\title{
Correction to: Thyroid 2013;23(12):1627-1637
}

N The December 2013 issue of Thyroid, (vol. 23, no. 12; 1627-1637), the article “Gestational Hypothyroidism Increases the Severity of Experimental Autoimmune Encephalomyelitis in Adult Offspring', by Albornoz et al. (1) requires a correction.

The funding source for Dr. Cecila Opazo for the above work was grant Fondecyt Postdoctorado 3130539. This information was missing in the online and the print version.

\section{Acknowledgments}

The authors are supported by the following grants: FONDECYT no. 11000926, FONDECYT no. 1070352, FONDECYT no. 1085281, FONDECYT no. 3070018, FONDECYT no. 3100090, FONDECYT no. 11075060 , FONDECYT no. 3130539, Millennium Institute on Immunology and Immunotherapy (P-09-016-F), Millennium Nucleus (P07-011-F), and Proyecto Interno Universidad Andrés Bello DI-01-44-08. L.J.C. is a Pew Latin American Fellow in the Biomedical Sciences.

The online version of the article has been corrected to reflect this change.

\section{Reference}

1. Albornoz EA, Carreño LJ, Cortes CM, Gonzalez PA, Cisternas PA, Cautivo KM, Catalán TP, Opazo MC, Eugenin EA, Berman JW, Bueno SM, Kalergis AM, Riedel CA 2013 Gestational hypothyroidism increases the severity of experimental autoimmune encephalomyelitis in adult offspring. Thyroid 23:1627-1637. 